\title{
Electron Microscopy Facility
}

National Cancer Institute

\section{Source}

National Cancer Institute. Electron Microscopy Facility. NCI Thesaurus. Code C16043.

A shared facility which provides services for electron microscopy. 